\title{
IDENTIDADE LOCAL DO ENSINO EM DESIGN DE MODA E RECONHECIMENTO NACIONAL
}

\section{LOCAL IDENTITY IN FASHION DESIGN EDUCATION AND NATIONAL RECOGNITION}

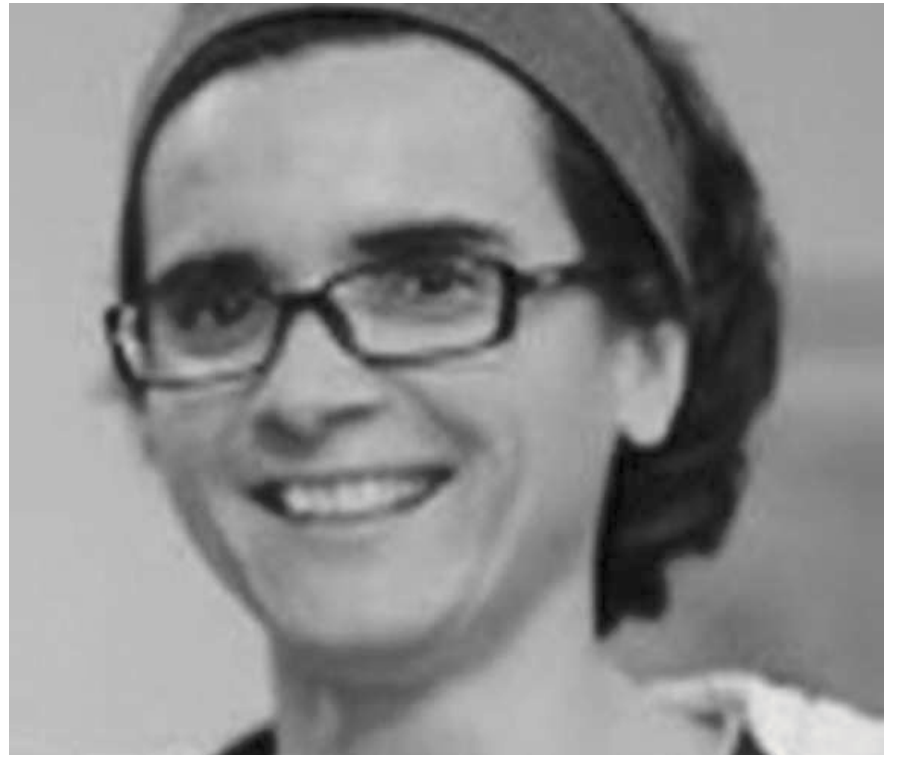

\section{Rita Salvado}

Doutora em Engenharia Têxtil pela Université de Haute Alsace e UBI.

Professora da Unidade I\&D Materiais Têxteis e Tecnologias Ambientais - FibEnTech Research Unit/ Universidade da Beira Interior - Portugal. rita.salvado@ubi.pt.

\section{RESUMO}

Acreditando que a forte herança industrial e a experiência da Universidade da Beira Interior (UBI) no ensino da engenharia têxtil permitem alavancar a formação em design de moda tornando-a sustentável e única no País, este artigo apresenta algumas actividades estrategicamente dinamizadas, nomeadamente a dinâmica do MOVE - Mostra Anual de trabalhos académicos e o workshop "ADN de Marca", e as suas contribuições para a consolidação da licenciatura em design de moda da UBI.Este artigo analisa como a afirmação desta proposta educativa no panorama nacional português, altamente concorrido, assentou na afirmação da sua identidade singular, alavancada numa forte herança tecnológica têxtil e indica perspectivas futuras de prosseguimento da consolidação e seu reconhecimento nacional e internacional. 


\section{PALAVRAS -CHAVE}

Ensino. Design de moda. Identidade.

\section{ABSTRACT}

Believing the strong industrial heritage plus the technological knowledge existing at Universidade da Beira Interior (UBI) may enhance the education on fashion design, making it sustainable and singular in the national context, this paper presents some actions strategically performed, mainly the dynamic MOVE - Annual Exhibition of Academic Works and the workshop about "Branding DNA". These actions have greatly contributed to the consolidation of the education on fashion design. This paper analyses how the recognition of the education in the national context was based and depended on the affirmation of a singular identity, which may be boosted by the local industrial cultural heritage.

\section{KEYWORDS}

Education. Fashion design. Identity.

\section{INTRODUÇÃO}

A Agenda Estratégica de Investigação da Plataforma Tecnológica Europeia (SRA, 2006), potencia há vários anos os materiais têxteis como materiais de eleição em novas aplicações e como guias de desenvolvimento de produtos personalizados que respondam às necessidades económicas e societais europeias. Recentemente, outra publicação da União Europeia (ACE, 2014) enfatiza a importância da herança cultural como um tópico central da Agenda Cultural Europeia, sublinhando o papel das tecnologias recentes e das novas abordagens científicas para o entendimento, preservação e disseminação cultural. Paralelamente, vários autores (TEUNISSEN, 2011;REINACH, 2011;HUGHES, 2011; RANTISI, 2011) têm analisado como as diversas identidades culturais nacionais potenciam o desenvolvimento da indústria da moda num contexto global.Assim, existe actualmente uma imensa actividade de inovação e desenvolvimento de materiais e tecnologias têxteis, que tem criado novas funções para os têxteis e tem trazido novos valores para a moda, que sendo um negócio global interpreta e integra especificidades culturais muito diversas. A Universidade da Beira Interior (UBI) reagiu a esta realidade propondo no ano de 2000 uma formação superior em 
design de moda, assente numa abordagem multidisciplinar e tecnológica, com base na sua longa experiência no ensino de engenharia têxtil. Este artigo analisa como a afirmação desta proposta educativa no panorama nacional português, altamente concorrido, assentou na identificação e posterior consolidação da sua identidade singular, alavancada numa forte herança tecnológicae cultural têxtil.

A UBI está localizada na Covilhã, cidade portuguesa conhecida como a "Manchester Portuguesa" pelo seu protagonismo na indústrialização têxtil dos séculos XIX e XX. Actualmente, ainda é na Covilhã que se concentra a indústria nacional da lã e se localizam referenciais da indústria de lanifícios europeia.Assim, no contexto territorial específico da UBI o património dos lanifícios é uma característica socio-cultural marcante, visível desde logo na arquitectura da cidade da Covilhã e da própria instituição UBI (LIMA e SALVADO, 2012).De facto, ao longo dos tempos, o encerramento e deslocalização de fábricas tem desactivado inúmeros edifícios industriais na cidade, alguns dos quaisa UBI tem convertido,desde 1975, em espaços universitários (WLODARCZYK, 2010). Em 1992, o Museu de Lanifícios da UBI foi inaugurado, abrindo ao público a recuperada Real Fábrica dos Panos do Marquês de Pombal, tinturaria criada em 1764 e classificada como património cultural nacional em 1982. Para além do Museu de Lanifícios, a UBI desenvolve a cultura, ciência e tecnologia têxteis através da educação e da investigação em engenharia têxtil (desde 1975) e em designtêxtil e de moda (desde 2000). A UBI está assim inserida num contexto com uma forte cultura industrial têxtil e dispõe de valências diversas que potenciam a aprendizagem e a interpretação desta cultura tecnológica.

\section{A OFERTA EDUCATIVA EM DESIGN DE MODA DA UBI}

A formação em design de moda da Universidade da Beira Interior (UBI) iniciou-se no ano 2000, com a criação da licenciatura em Design Têxtil e do Vestuário. Posteriormente, em 2005, o curso foi reestruturado de acordo com a Declaração de Bolonha, criando-se a licenciatura e o mestrado em Design de Moda. Em 2010, foi criado o mestrado em Branding e Design de Moda, em colaboração com o IADE-U (Instituto de Arte, Design e Empresa Universitário). No ano de 2011, os planos curriculares foram reestruturados. Recentemente, já em 2014, foi criado o doutoramento em Design de Moda, em colaboração com a UM (Universidade do Minho). Actualmente, a oferta 
formativa em ciência e tecnologia têxteisda UBI contempla os três ciclos de ensino superior em design de moda (licenciatura, mestrados e doutoramento) e o doutoramento em engenharia têxtil.

Este artigo apresentaa estratégia de consolidação da licenciatura em design de moda, que sendo um primeiro ciclo de formação superior é essencial para a estabilidade dos ciclos seguintes: mestrados (segundo ciclo) e doutoramento (terceiro ciclo).

\subsection{CONTEXTO NACIONAL PORTUGUÊS}

No sistema educativo nacional português existem actualmente seis escolas de ensino superior que ministram formação em design de moda, as quais são indicadas na lista abaixo, onde as quatro primeiras são instituições públicas e as duas últimas são privadas:

- A Faculdade de Arquitectura da Universidade de Lisboa (licenciatura e mestrado);

- A UM - Universidade do Minho (licenciatura, mestrado e doutoramento - este último em cooperação com a UBI);

- A Universidade da Beira Interior (licenciatura, mestrados e doutoramento, sendo um mestrado em cooperação com o IADE-U e o doutoramento em cooperação com a UM);

- A ESART - Escola Superior de Artes Aplicadas do Instituto Politécnico de Castelo Branco (licenciatura e mestrado);

- A ESAD - Escola Superior de Artes e Design de Matosinhos (licenciatura e mestrado);

- O IADE-U Instituto de Arte, Design e Empresa - Universitário, em Lisboa (mestrado em cooperação com a UBI).

Neste contexto, e considerando a proximidade geográfica entre Covilhã e Castelo Branco, a formação da UBI tem grande concorrência nacional e regional.

\subsection{A LICENCIATURA EM DESIGN DE MODA DA UBI}

A licenciatura em Design de Moda da UBI é um curso superior de primeiro ciclo, de três anos lectivos (seis semestres), e um total de 180 ECTS (European Credit Transfer System) que correspondem a cerca de 4800 horas de trabalho dos alunos (800 horas por semestre). 
A criação, em 2000, de uma licenciatura em Design Têxtil e do Vestuário, respondia a uma necessidade profissional da indústria têxtil e da moda portuguesa, mas também a uma visão de dinamização do Departamento de Ciência e Tecnologia Têxteis da UBI, com longa experiência no ensino da Engenharia Têxtil; todavia que se debatia com a progressiva e preocupante falta de alunos nesta área. Desde a sua criação, a licenciatura em Design Têxtil e do Vestuário procurou integrar a cultura industrial dos lanifícios e da cidade da Covilhã nas práticas académicas através de algumas acções, nomeadamente do evento CAPA 05 (LIMA, 2012). O evento CAPA, em 2005, foi constituído por exposições, palestras e desfile, que consistiu em actividade interdisciplinar entre moda e multimédia. $O$ evento foi um estimulo à criação de um espaço de debate e de confrontação criativa, de opiniões, de divulgação de ideias e projectos valorizando-se a exposição pública de trabalhos como outro momento essencial de aprendizagem, potenciador de colaborações entre discentes, docentes e agentes da comunidade.

A seguinte tabela (tab.1) apresenta a evolução da licenciatura ao longo dos anos, através dos resultados do concurso nacional de acesso ao ensino superior, disponibilizados pela DGES - Direcção Geral do Ensino Superior de Portugal. A tabela apresenta a classificação de entrada (classificação média do último aluno colocado, de 0-20 valores), o número de vagas, o número de colocados e o índice de procura (IProcura $=N^{\circ}$ referências $1^{\text {a }}$ opção $/ N^{\circ}$ Vagas) do curso. 
Tabela 1 - Evolução do curso de primeiro ciclo em Design de Moda da UBI

\begin{tabular}{|l|cccc|}
\cline { 2 - 5 } \multicolumn{1}{c|}{} & \multicolumn{4}{c|}{ UBI-Dmoda } \\
Média & № Vagas & No coloc & IProcura \\
\hline set-00 & 124,8 & 30 & 30 & \\
set-01 & 135,3 & 30 & 30 & \\
set-02 & 137,2 & 30 & 30 & \\
set-03 & 128,5 & 30 & 30 & 0,63 \\
set-04 & 125,6 & 30 & 30 & 0,37 \\
set-05 & 112,5 & 30 & 30 & 0,43 \\
set-06 & 110,4 & 40 & 25 & 0,3 \\
set-07 & 125,4 & 40 & 40 & 0,28 \\
set-08 & 124,6 & 40 & 40 & 0,45 \\
set-09 & 131,7 & 40 & 40 & 0,55 \\
set-10 & 133,9 & 40 & 40 & 0,9 \\
set-11 & 132,4 & 40 & 40 & 0,7 \\
set-12 & 126,8 & 40 & 40 & 0,73 \\
set-13 & 131,2 & 40 & 43 & 0,9 \\
set-14 & 131,3 & 50 & 50 & 0,78 \\
\hline
\end{tabular}

Fonte: dados da DGES

Após uma fase inicial de boa recepção pela comunidade do curso de Design Têxtil e do Vestuário, o curso começou no entanto a apresentar índices de qualidade decrescentes. Assim, após a bem sucedida fase inicial de arranque do funcionamento do curso, era necessário consolidar a formação, potenciando a experiência e a maturidade adquiridas. A mudança de direcção de curso em novembro de 2006 permitiu ajustar a estratégia de consolidação do curso, focando-a na afirmação de uma identidade singular, alavancada na herança e no conhecimento tecnológico da região.

\section{AFIRMAÇÃO DA IDENTIDADE DA LICENCIATURA EM DESIGN DE MODA DA UBI}

Acreditando que a forte herança industrial e o conhecimento tecnológico permitem alavancar a formação em Design de Moda, tornando-a sustentável e única no País, este artigo analisa as várias acções pedagógicas e científicas desenvolvidas articuladamente entre os anos de 2007 e 2012 e as suas contribuições para a afirmação da identidade da licenciatura em Design de Moda. 
O projecto de afirmação da identidade do primeiro ciclo em Design de Moda da UBI se iniciou, assim, em 2007 e visou:

- definir e consolidar a identidade da formação ministrada na UBI e na Covilhã;

- consolidar o primeiro ciclo em Design de Moda e torna-lo sustentável no sistema educativo nacional;

- aumentar a sinergia entre Engenharia Têxtil e Design de Moda;

- potenciar a herança cultural em torno dos lanifícios e a intervenção do Design de Moda na dinamização cultural e económica da região;

- promover a cooperação entre os departamentos envolvidos no funcionamento do curso e a melhoria do seu funcionamento prático.

O projecto teve as seguintes fases de desenvolvimento:

- $1^{a}$ (primeira) Fase: aferição de experiências e perspectivas sobre o curso;

- $\quad 2^{a}$ (segunda) Fase: identificação da identidade;

- $\quad 3^{a}$ (terceira) Fase: consolidação da identidade e da formação.

O gráfico seguinte ilustra o desenvolvimento das várias fases ao longo dos anos e as acções mais importantes em cada uma delas. O projecto de afirmação da identidade do curso decorreu sempre paralelamente à realização dos eventos MOVE - Mostra de Design de Moda, que replicaram anualmente a anterior experiência do CAPA.

Figura 1 - Fases de desenvolvimento do Projecto de afirmação da identidade

19 Fase: aferição de experiências e perspectivas sobre o curso Questionários aos alunos

MOVE - Exposição, Palestras e Workshops

MOVE 07 MOVE 08/09 MOVE 09/10 MOVE 11 MOVE 12 MOVE 13

2a Fase: identificação de identidade

Workshop "ADN de marca"

MOVE - Exposição, Palestras e Workshops

MOVE 07 MOVE 08/09 MOVE 09/10 MOVE 11 MOVE 12 MOVE 13

3a Fase: consolidação da identidade e da formação

Programa de Aprofundamento de Bolonha

MOVE - Exposição, Palestras e Workshops

MOVE 07 MOVE 08/09 MOVE 09/10 MOVE 11 MOVE 12 MOVE 13

\begin{tabular}{l|l|l|l|l|l|}
2007 & 2008 & 2009 & 2010 & 2011 & 2012
\end{tabular}

Fonte: do(s) autor(es) 
1a Fase: aferição de experiências e perspectivas sobre o curso

A primeira fase de desenvolvimento do projecto assentou na recolha e análise de experiências e perspectivas sobre o curso junto aos alunos e aos professores. A intervenção foi iniciada com a realização de questionários junto aos alunos para análise do curriculum. Esses questionários visaram analisar a relevância e o equilíbrio da estrutura curricular e recolher propostas de optimização curricular, de conteúdos a considerar, de cooperação entre disciplinas e de melhoria do funcionamento prático (horários, funcionamento por módulos, etc). Os questionários foram aplicados entre o ano de 2008 e o ano de 2011 e permitiram recolher informação que norteou a reestruturação do curso, efectuada em julho 2011. Desta forma, incluíram-se os alunos no processo de reestruturação do curriculum.

A fase incluiu também a realização do evento MOVE - Mostra de Design de Moda, que incluiu exposições, workshops e palestras para promover a reflexão em torno do curso e da moda em geral. A exposição anual de trabalhos no Museu de Lanifícios promoveu a partilha do trabalho efectuado em diversas unidades curriculares. Esta partilha potenciou a cooperação entre unidades curriculares dos primeiro e segundo anos da licenciatura. A exposição anual do MOVE deu também à direcção de curso uma base de conhecimento que orientou a optimização do curriculum em termos de encadeamento de conteúdos, de complementaridade de metodologias e de eliminação de redundâncias.

\section{2a Fase: identificação da identidade}

O marco determinante no desenvolvimento desta fase foi a realização do workshop "ADN da marca da licenciatura em Design de Moda da UBI", pelo Prof. Luiz Salomão Ribas Gomez, da Universidade Federal de Santa Catarina, Brasil, em fevereiro de 2010, no âmbito do MOVE. Neste workshop, onde participaram 31 alunos e 3 professores, a metodologia "ADN de marca", metodologia usada em marketing e em branding (GOMEZ, 2011), foi aplicada à análise da identidade do curso e à identificação das características únicas e diferenciadoras do curso da UBI, relativamente a outros cursos de Design de Moda.

A metodologia "ADN de marca" (GOMEZ, 2011) permitiu ao longo do workshop identificar quatro atributos específicos ao primeiro ciclo de Design 
de Moda da UBI, que constituem o seu ADN e que são:

- Tecnológico (têxtil e vestuário)

- Funcional

- Eclético (Tradicional vs. Contemporâneo)

- Promotor de desenvolvimento pessoal.

Esta lista de atributos foi determinante e orientadora da reestruturação do curso efectuada em julho de 2011.

Para além do workshop de "ADN de marca", outras actividades do MOVE se realizaram com o objectivo deliberado de promover a exploração de técnicas, materiais e tecnologias. Os programas dos vários MOVE recorrentemente remetem para a aprendizagem de como ligar a tecnologia ao design de moda. Desta forma, promoveu-se o "aprender fazendo", explorando as tecnologias têxteis e visando potenciar os muitos recursos existentes na UBI.

As actividades extracurriculares realizadas no âmbito do MOVE visaram também promover a cooperação com o Museu de Lanifícios, utilizando as diversas valências do Museu e dando-as a conhecer aos alunos; desde as exposições permanentes, ao centro de documentação e à base de amostras têxteis, passando pelo espaço expositivo e pelas oficinas de tecelagem. Esta cooperação fortaleceu enormemente a abordagem pedagógica à herança cultural dos lanifícios, disponibilizando ferramentas de trabalho aos alunos de Design de Moda. Nesta dinâmica, as ferramentas foram dadas a conhecer aos alunos e professores, embora a sua utilização ainda não esteja potenciada e requeira acções específicas para além da exposição.

\section{3a Fase: consolidação da identidade e da formação}

A consolidação da identidade do curso foi sendo trabalhada ao longo das várias actividades do MOVE, sempre em complementaridade ao trabalho desenvolvido no "Programa de Aprofundamento de Bolonha". A participação neste programa, em curso na UBI sob orientação da Pró-Reitora Isabel Neto, deu método e permitiu estruturar a análise do curriculum, nomeadamente a definição do perfil do curso, a análise das competências gerais do curso e as contribuições individuais das várias disciplinas. Este trabalho culminou com a reestruturação do curso em julho de 2011, o que permitiu optimizar o curriculum de acordo com a identidade anteriormente definida. A reestruturação permitiu enquadrar curricularmente algumas das acções do MOVE, especificamente a 
exposição de trabalhos, e consolidar o perfil de curso.

Posteriormente, a consolidação da identidade do curso incluiu uma abordagem transversal nas disciplinas dos primeiro e segundo anos de temas sobre a cultura local dos lanifícios. Esta experiência foi completada com a realização de visitas de estudos ao museu, às fábricas e ao patrimônio industrial da Covilhã. As palestras do MOVE também contribuíram para esta fase, abordando temas estratégicos e articulados com as restantes acções.

Esta dinamização de acções promoveu a aprendizagem dos alunos pela aquisição de atitudes, sobretudo de:

- reflexão e discussão de ideias,

- exploração de técnicas e materiais,

- olhar atento ao mundo e às pessoas,

- sustentabilidade,

- pro-actividade, e

- empreendedorismo.

Este tipo de aprendizagem é determinante para o desenvolvimento pessoal e cultural do indivíduo e do designer de moda.

\section{AVALIAÇÃO E REFLEXÕES SOBRE A INTERVENÇÃO}

A tabela 2 apresenta dados da DGES (Direcção Geral do Ensino Superior de Portugal) que ilustram a evolução dos cursos de primeiro ciclo em Design de Moda em instituições públicas nacionais (Portugal): Universidade da Beira Interior (UBI), Faculdade de Arquitectura da Universidade de Lisboa (FAUL), Universidade do Minho (UM) e Escola Superior de Artes Aplicadas do Instituto Politécnico de Castelo Branco (ESART). A tabela mostra a média de entrada (nota do último colocado), o número de colocados (indicando-se em vermelho se inferior ao número de vagas) e do índice de procura (IProcura = No referências $1^{\text {a }}$ opção / No Vagas) dos cursos. 
Tabela 2 - Evolução dos cursos de primeiro ciclo em Design de Moda

\begin{tabular}{|c|c|c|c|c|c|c|c|c|c|c|c|c|c|c|c|c|}
\hline & \multicolumn{4}{|c|}{ UBI-Dmoda } & \multicolumn{4}{|c|}{ FA-UL } & \multicolumn{4}{|c|}{ UM } & \multicolumn{4}{|c|}{ ESART } \\
\hline & Média & № Vagas & № coloc & IProcura & Média & № Vagas & № coloc & IProcura & Média & № Vagas & lo coloc & IProcura & Média & № Vaga & № coloc & IProcura \\
\hline set-00 & 124,8 & 30 & 30 & & & & & & & & & & & & & \\
\hline set-01 & 135,3 & 30 & 30 & & & & & & & & & & & & & \\
\hline set-02 & 137,2 & 30 & 30 & & & & & & & & & & & & & \\
\hline set-03 & 128,5 & 30 & 30 & 0,63 & & & & & & & & & & & & \\
\hline set-04 & 125,6 & 30 & 30 & 0,37 & & & & & & & & & & & & \\
\hline set-05 & 112,5 & 30 & 30 & 0,43 & & & & & & & & & & & & \\
\hline set-06 & 110,4 & 40 & 25 & 0,3 & & & & & & & & & & & & \\
\hline set-07 & 125,4 & 40 & 40 & 0,28 & & & & & & & & & & & & \\
\hline set-08 & 124,6 & 40 & 40 & 0,45 & 152,3 & 31 & 31 & & 145,6 & 30 & 30 & & 134,1 & 30 & 30 & \\
\hline set-09 & 131,7 & 40 & 40 & 0,55 & 157,3 & 31 & 31 & & 152 & 30 & 30 & & 130,1 & 30 & 30 & \\
\hline set-10 & 133,9 & 40 & 40 & 0,9 & 153 & 31 & 31 & 1,71 & 139,6 & 30 & 30 & 1,5 & 127 & 38 & 38 & 0,53 \\
\hline set-11 & 132,4 & 40 & 40 & 0,7 & 149,8 & 31 & 31 & 2 & 148 & 30 & 30 & 2,6 & 124,5 & 35 & 35 & 0,57 \\
\hline set-12 & 126,8 & 40 & 40 & 0,73 & 142,3 & 46 & 46 & 1,07 & 148,8 & 30 & 31 & 2,27 & 110 & 35 & 30 & 0,54 \\
\hline set-13 & 131,2 & 40 & 43 & 0,9 & 144 & 46 & 47 & 1,17 & 148 & 30 & 30 & 2,4 & 120,1 & 35 & 35 & 0,57 \\
\hline set-14 & 131,3 & 50 & 50 & 0,78 & 149,3 & 46 & 46 & 1,26 & 150,8 & 30 & 30 & 2,2 & 130,2 & 30 & 30 & 0,90 \\
\hline
\end{tabular}

Fonte: dados da DGES

Como pode-se observar, no panorâma nacional a evolução dos vários cursos foi diversa, não revelando uma tendência única. Assim, a evolução dos dados apresentados na tabela 2 revela uma consolidação da licenciatura da UBI no período do projecto, através do aumento da classificação média de entrada dos alunos e do índice de procura. A ocorrência do primeiro MOVE, no mês de julho de 2007, a dinâmica dos MOVE nos anos seguintes e o projecto de afirmação da identidade do curso muito contribuiram para o crescimento gradual do índice de procura do curso entre os anos de 2007 e 2014.

Em termos institucionais, o primeiro ciclo em Design de Moda distanciase dos outros primeiros ciclos em Design ministrados na UBI (Design Industrial e Design Multimedia) por apresentar um índice de procura superior, como se pode verificar na tabela seguinte (tab.3).

Tabela 3 - Evolução dos cursos de primeiro ciclo em Design da UBI

\begin{tabular}{|c|c|c|c|c|c|c|c|c|c|c|c|c|}
\hline & \multicolumn{4}{|c|}{ UBI-Dmoda } & \multicolumn{4}{|c|}{ UBI-DInd } & \multicolumn{4}{|c|}{ UBI-DMMedia } \\
\hline & Média & № Vagas & № coloc & IProcura & Média & № Vagas & № coloc & IProcura & Média & № Vagas & № coloc & IProcura \\
\hline set-06 & 110,4 & 40 & 25 & 0,3 & & & & & & & & \\
\hline set-07 & 125,4 & 40 & 40 & 0,28 & & & & & & & & \\
\hline set-08 & 124,6 & 40 & 40 & 0,45 & 119,8 & 30 & 30 & & 120,1 & 40 & 40 & \\
\hline set-09 & 131,7 & 40 & 40 & 0,55 & 130,4 & 30 & 30 & & 130,9 & 40 & 40 & \\
\hline set-10 & 133,9 & 40 & 40 & 0,9 & 132,6 & 30 & 30 & 0,5 & 130,2 & 40 & 40 & 0,38 \\
\hline set-11 & 132,4 & 40 & 40 & 0,7 & 117,4 & 30 & 30 & 0,5 & 121,7 & 40 & 40 & 0,55 \\
\hline set-12 & 126,8 & 40 & 40 & 0,73 & 115,3 & 30 & 31 & 0,37 & 130,2 & 40 & 40 & 0,4 \\
\hline set-13 & 131,2 & 40 & 43 & 0,9 & 110,4 & 35 & 29 & 0,46 & 120,4 & 40 & 40 & 0,53 \\
\hline set-14 & 131,3 & 50 & 50 & 0,78 & 112,8 & 35 & 36 & 0,63 & 112,6 & 40 & 40 & 0,43 \\
\hline
\end{tabular}

Fonte: dados da DGES 
Para além do contributo na consolidação do curso, outro importante resultado do projecto de afirmação da identidade é a criação de um ambiente de cultura e pro-actividade. Neste sentido, é de realçar o movimento Expand Your Mind (EYM, 2013) que os alunos de Design de Moda criaram. Este movimento visa promover uma plataforma livre onde os alunos, independentemente das identidades educativas, possam expressar o seu potencial artístico (EYM, 2013). Este movimento é revelador da maturidade cultural e da pro-actividade dos alunos.

Ainda que não haja relação directa entre o projecto de afirmação da identidade e o movimento Expand Your Mind, há uma forte identificação entre os dois, e na minha interpretação, o bom ambiente criado pelo MOVE propiciou o surgimento do activismo Expand Your Mind.

O impacto deste projecto na consolidação da formação é difícil de quantificar directamente. No entanto, a análise dos dados da DGES, relativos ao acesso ao ensino público português, permitem constatar o estado de consolidação do curso, para a qual este projecto contribuiu.

\section{CONCLUSÃO}

A Covilhã, cidade Portuguesa com 52.000 habitantes e 7.500 estudantes oriundos de todo o país (Portugal) e alguns estrangeiros, apresenta uma cultura industrial que a Universidade da Beira Interior, através das suas diversas valências, Museu de Lanifícios, ensino e investigação em têxtil e em moda, tem procurado potenciar.

O projecto de afirmação da identidade da licenciatura em Design de Moda foi determinante na consolidação da formação e consequente credibilização junto à academia e à opinião pública. Os resultados do projecto orientaram a reestruturação do curso, que permitiu optimizar o curriculum e motivar os alunos. A consolidação da identidade criou um ambiente de proactividade e de reflexão em torno do design de moda, ambiente propício ao surgimento de ideias e de outros projectos. Finalmente, este projecto permitiu estruturar uma dinâmica de aprendizagem de valores e atitudes, que precisa constantemente de ser alimentada e continuada.

Acreditando que a forte herança industrial e o conhecimento tecnológico têxtil permitem alavancar a formação em Design de Moda, foram dinamizadas algumas actividades extracurriculares que contribuiram com relevância para a afirmação da identidade da licenciatura em Design de 
Moda e a sua consolidação. Nomeadamente a dinâmica do MOVE, mostra anual de trabalhos acadêmicos, tem promovido uma reflexão conjunta com outras universidades, indústria, profissionais, museus, escolas secundárias e comunidade em geral, em torno do design de moda. Além disso, o workshop "ADN de Marca", permitiu identificar o perfil da licenciatura com seis características: tecnológico, funcional, eclético (tradicional, contemporâneo) e promotor de desenvolvimento pessoal; as quais têm norteado o desenvolvimento do curso da UBI.

As actividades extracurriculares desenvolvidas no âmbito do projecto permitiram colmatar lacunas pedagógicas e de conteúdos, formar professores e aumentar a motivação dos alunos. Sendo actividades intensivas, são muito profícuas em termos de aprendizagem e motivação. O projecto foi eficiente na disseminação de valores e na promoção da aquisição de atitudes por envolver alunos e professores numa dinâmica promotora da reflexão e da pro-actividade. $\mathrm{O}$ ambiente informal de trabalho das actividades extracurriculares potenciou o envolvimento e a motivação dos alunos no processo de aprendizagem.

\section{AGRADECIMENTOS}

O desenvolvimento deste trabalho só foi possível graças ao envolvimento dos alunos e dos muitos professores do curso que pontualmente, ou continuadamente como os Professores Elsa Lima, David Gorjão, Sílvia Soares e Cláudia Teixeira, participaram nas acções. Agradeço a todos a participação. Agradeço ao Presidente do Departamento de Ciência e Tecnologia Têxteis - Prof. Rui Miguel o apoio. Agradeço à Profa Isabel Neto, Pró-Reitora da UBI, a orientação no programa de Aprofundamento de Bolonha. Agradeço ainda ao Prof. Luiz Salomão Ribas Gomez a disponibilidade para realizar o workshop "ADN de marca", marco fundamental deste projecto, e aos Professores Paulo Duarte e Arminda do Paço por nele terem participado. Finalmente, agradeço à minha colega Elsa Lima a partilha profícua de ideias que alimentaram o desenvolvimento de todo este trabalho e a inspiração na designação MOVE, com a qual tanto me identifico. 


\section{REFERÊNCIAS}

EUROPEAN COMISSION. Communication from the Commission to the European Parliament, the Council, the European Economic and Social Committee and the Committee of the Regions: Towards an integrated approach to cultural heritage for Europe. Brussels, 2014. Disponível em: <http:// ec.europa.eu/culture/library/publications/2014-heritage-communication_en.pdf>. Acesso em: 22 setembro 2014.

EYM - MOVIMENTO EXPAND YOUR MIND. 2013. Disponível em: <http://www. movimentoexpandyourmind.com/>; $1^{\circ}$ episódio- <http://vimeo.com/62120234>; $2^{\circ}$ episódio-<http://vimeo.com/63594210>;3 episódio- <http://vimeo. com/67089265>. Acesso em: 31 out 2014.

GOMEZ, Luiz Salomão Ribas; OLHATS, Magali; FLORIANO, Juliana e VIEIRA, M.L.H.. O DNA da marca de moda: o processo. In: A Moda num Mundo Global, ed. Vida Económica, Porto, p.131-155, 2011.

HUGHES, C.; BELL, D.; WOOFF, D. Underpinning the STEM Agenda through Technological Textiles? An Exploration of Design Technology Teachers' Attitudes. Design and Technology Education: An International Journal, 16(1) pp. 53-61; 2011.

LIMA, Elsa.Creativity and sustainability in fashion design Education. Global Fashion Conference: Future Options for the Fashion World, Madrid, 15-17 Novembro 2012.

LIMA, Elsa; SALVADO, Rita. Sustentabilidade no Ensino Superior em Design de Moda - Análise de estratégias e iniciativas locais. DESIGNA 12 UN/ SUSTAINABALITY - International Conference on Design Research, Covilhã, 22-23 Novembro 2012.

RANTISI, N.M.; The Prospects and Perils of Creating a Viable Fashion Identity. Fashion Theory, 15 (2) pp. 259-266, 2011.

REINACH, S.S.; National Identities and International Recognition. Fashion Theory,15 (2) pp. 267-272, 2011.

Strategic Research Agenda of the European Technology Platform -Future of Textiles and Clothing. Disponível em: <http://www.textile-platform.eul>. Acesso em: 22 setembro 2014.

TEUNISSEN, José; Deconstructing Belgian and Dutch Fashion Dreams: From Global Trends to Local Crafts. Fashion Theory,15 (2) pp. 157-176, 2011. 
WLODARCZYK, Anna Marta.Industrial Spaces for Public Use: "UBI AREA” in Covilhã Portugal, ACEE, 4, p.37-48, 2010.

Recebido em: 22/09/2014; Aceito em: 07/10/2014.

Esta obra foi licenciada com uma Licença Creative Commons.
Rita Salvado é portuguesa e nasceu em 1969. Doutorou-se em Engenharia Têxtil com doutoramento europeu - Portugal, França e Suécia - pela Université de Haute Alsace e pela UBI em 2002. Foi directora da licenciatura em design de moda da UBI, entre Novembro 2006 e Novembro 2013, e coordenadora ERASMUS entre Setembro 2004 e Janeiro 2014. Escreveu mais de 50 publicações em conferências e revistas científicas. Em 2003 recebeu o prémio"The Fiber Society Student Award" para o melhor artigo submetido no ano 2003. Em 2013 recebeu o prémio de Mérito Pedagógico Universidade da Beira Interior - Faculdade de Engenharia/Caixa Geral de Depósitos 2013 pelo trabalho desenvolvido em prol da consolidação da identidade da licenciatura em Design de Moda. Os seus interesses actuais de investigação assentam na sinergia entre Engenharia Têxtil e Design de Moda, nomeadamente em tecnologia para vestir (wearable Technology). 